O COMPONENTE ÉTNICO NO LICENCIAMENTO AMBIENTAL DE GRANDES PROJETOS DE DESENVOLVIMENTO: A INVISIBILIZAÇÃO DAS COMUNIDADES QUILOMBOLAS DE SANTARÉM/PA

THE ETHNIC COMPONENT IN THE ENVIRONMENTAL LICENSING OF

LARGE-SCALE DEVELOPMENT PROJECTS: THE INVISIBILIZATION OF QUILOMBOLAS COMMUNITIES IN SANTARÉM/PA (BRAZIL)

Diego Pérez

Como citar este artigo:

PÉREZ, Diego. O componente étnico no licenciamento ambiental de grandes projetos de desenvolvimento: a invisibilização das comunidades quilombolas de Santarém/PA. In: Cadernos do Lepaarq, v. XVI, n.31., p. 121-133, Jan-Jun. 2019. 


\title{
O componente étnico no licenciamento ambiental de grandes projetos de desenvolvimento: a invisibilização das comunidades quilombolas de Santarém/PA
}

\author{
Diego Pérez Ojeda del Arco*
}

Resumo: O objetivo deste artigo é apresentar uma reflexão sobre algumas das limitações que um licenciamento ambiental de um grande projeto de desenvolvimento pode apresentar ao lidar com a presença de grupos organizados a partir do reconhecimento das suas respectivas identidades étnicas. Dessa forma, serão abordados aspectos do processo de invisibilização de comunidades quilombolas representadas pela Federação das Organizações Quilombolas de Santarém (FOQS/PA). Isso será feito a partir da análise dos Estudos e Relatórios de Impacto Ambiental (EIA/RIMA) elaborados para responder a viabilidade ou não da construção de um porto exportador de grãos sólidos, que seria construído como parte de um projeto desenvolmentista para a região norte do país.

\section{Palavras Chave:}

Licenciamento Ambiental; Comunidades Quilombolas; Baixo Amazonas; Projetos de "desenvolvimento".

\begin{abstract}
The purpose of this article is to reflect on some of the limitations that environmental licensing of a major development project can present when dealing with the presence of organized groups from the recognition of their respective ethnic identities. In this way, aspects of the process of invisibilization of quilombola communities organized around the Federation of Quilombola's Organizations of Santarém (FOQS/PA) will be approached. This will be done by analyzing the Environmental Impact Studies and Reports (EIA / RIMA) prepared to answer the feasibility or otherwise of the construction of a solid grain export port, which would be built as part of a development project for the northern region of the country.
\end{abstract}

\section{Keywords:}

Environmental Licensing; Quilombola population; Lower Amazon; "Development" projects.

\footnotetext{
* Bacharel em Antropologia pela Universidade Federal Fluminense- UFF. Mestrando em Antropologia Social no PPGA da Universidade Federal do Pará- UFPA. Grupo de Estudos Amazônicos-GEAM/UFF. Email: diegoperezojedadelarco@gmail.com
} 


\section{INTRODUÇÃO}

Os ataques decorrentes do desmantelamento de políticas públicas que começaram a ser efetivados desde o primeiro dia de governo do presidente Jair Bolsonaro já se refletem em retrocessos ligados ao campo socioambiental, pondo em evidencia a atuação da autointitulada Frente Parlamentar da Agropecuária (FPA). Esses processos, porém, não são uma novidade para a também chamada "bancada ruralista", a qual, ao longo dos últimos anos, tentou propor e aprovar a maior quantidade de Projetos de Decretos Legislativos (PDLs), Medidas Provisórias (MPs) e Projetos de Lei (PLs), como parte do empenho constante por beneficiar e potenciar os interesses daqueles setores que abertamente defendem.

Nesse sentido, um dos Projetos de Lei (PL) que a bancada vem pondo em questão desde finais de 2016 é a PL $\mathbf{n}^{\circ}$ 3.729/2004 ${ }^{1}$, apresentada pelo então deputado Mauro Pereira (PMDB-RS). Na prática, a PL, que se encontra agora na pauta da Comissão de Finanças e Tributação da Câmara (CFT), pretende flexibilizar o atual sistema de licenciamento ambiental. Em maio de 2017 o Instituto Brasileiro do Meio Ambiente e dos Recursos Naturais Renováveis (Ibama) publicou uma análise detalhada sobre a mesma, concluindo "não ter condições técnicas ou jurídicas de prosperar sem modificações profundas"2.

Fica evidente que a aprovação de uma PL como essa se refletiria numa série de ameaças para a seguridade socioambiental do país, cujo sistema de licenciamento ambiental atual vem apresentando limitações, especialmente quando lida com a presença de grupos organizados pelo critério de autoreconhecimento étnico. Com isso, o trabalho se pauta na reflexão sobre as diferentes invisibilizações a que foram sujeitadas as comunidades organizadas na Federação das Organizações Quilombolas de Santarém (FOQS), a partir do Estudo e Relatório de Impacto Ambiental (EIA/RIMA) realizado como mecanismo obrigatório no processo de licenciamento ambiental requerido pela Empresa Brasileira de Portos de Santarém (EMBRAPS), que tinha o objetivo de instalar um terminal portuário voltado ao escoamento de soja.

\section{CONTEXTUALIZAÇÃO}

No dia primeiro de junho de 2017 se noticiou em vários meios de comunicação que, após oito trimestres seguidos de recessão, o aumento de $1,1 \%$ no PIB, referente ao primeiro trimestre daquele ano, mostrava que tecnicamente Brasil tinham saído da crise. Uma análise mais aprofundada revelava que o aumento se deu em grande parte em função do crescimento de 13,4\% do setor agropecuário, que passou a ser denominado como o novo "carro chefe da economia”. Só no que diz respeito ao cultivo da soja, segundo dados fornecidos pela Empresa Brasileira de Pesquisa Agropecuária (EMBRAPA) ${ }^{3}$, o país produziu durante o ano de 2016 uma quantidade de 113,923 milhões de toneladas, se mantendo como o segundo maior produtor de soja a nível mundial, perdendo só para os Estados Unidos ${ }^{4}$.

1 Projeto de Lei $\mathrm{n}^{\circ}$ 3.729, de 2004. Disponível em: <https://www.camara.gov.br/proposicoesWeb/prop_mostrarintegra?codteor=1592274\&filename=Parecer-CFT-29-08-2017>. 27/04/2017. Acessado em: 14/12/2018.

2 Parecer n ${ }^{\circ}$ 001/2017- Presidência/IBAMA. Análise da proposta mais recente encaminhada pela Frente Parlamentar da Agropecuária para a Lei Geral do Licenciamento Ambiental. Disponível em: <http://www.ibama.gov.br/phocadownload/noticias/noticias2017/parecer_001_2017_e_anexos.pdf>. 05/05/2017. Acessado em: 18/12/2018.

3 Instituição pública vinculada ao hoje em dia único Ministério de Agricultura, Pecuária e Abastecimento (MAPA) devido à desaparição do Ministério de Agricultura Familiar e Desenvolvimento Agrário (MDA) como resultado das reformas efetuadas pelo governo Temer.

4 Nos dados apresentados pela EMBRAPA referentes à safra 2017/2018 se evidencia um aumento na produção de soja no Brasil, que chegou aos 116,996 milhões de toneladas. Os Estados Unidos continuam sendo o maior produtor de soja a nível mundial com 119,518 milhões de toneladas. Porém as distancias entre ambos países vem-se reduzindo exponencialmente. Soja em números (safra 2017/2018). Disponível em:<https://www.embrapa.br/soja/cultivos/soja1/dados-economicos>. maio de 2018. Acessado em: 18/12/18.

PÉREZ, Diego. O componente étnico no licenciamento ambiental de grandes projetos de desenvolvimento... In: Cadernos do Lepaarq, v. XVI, 
Como demostram as estatísticas, a grande preocupação da agroindústria diante destes commodities não gira em torno à sua produção, que inclusive se encontra em um dos seus melhores momentos. O que realmente os preocupa é a maneira como estes produtos serão exportados. Os Portos de Santos/SP e Paranaguá/PR, localizados ao Sudeste e Sul do Brasil respetivamente, foram por muito tempo as rotas prediletas dos navios cargueiros de grãos e cereais para a exportação. Porém, com o aumento exponencial da produção de soja e trigo, estes portos têm esgotado a sua capacidade de exportação. Por isso, uma das principais apostas recentes, tanto do agronegócio quanto do Estado brasileiro, cujos interesses as vesses se confundem, tem sido a invenção do chamado Arco Norte. Nas próprias palavras do atual presidente da Câmera de deputados, Rodrigo Maia (DEM):

[...] (O Arco Norte) propõe a implantação de uma nova logística intermodal de transporte que vai, a um só tempo, diminuir a pressão sobre os portos da Região Sudeste e aproximar mais os produtores nacionais de nossos parceiros comerciais no resto do mundo. (Presidente da Câmera de deputados Rodrigo Maia - grifos meus) ${ }^{5}$.

Assim, pode-se observar como o projeto do Arco Norte, ao propor soluções especificas para continuar com as exportações e inclusive incrementa-las, reflete a lógica capitalista do mercado moderno, o qual deve-se encontrar, por via de regra, sempre em constante expansão. Vários autores têm indagado sobre o tema, dentre eles Karl Polanyi, quem se questionou sobre a natureza daquele "molinho satânico" que transforma aos homens em massa. Em sua obra, A grande transformação, Polanyi retoma o processo histórico de Cercamento dos campos na Inglaterra do século XVI, acreditando encontrar ali a gênese daquele sistema que conseguiu transformar por completo os tecidos sociais das relações entre os homens. Segundo ele, o estabelecimento da economia de mercado como esfera autônoma da sociedade conseguiu implantar "um novo credo totalmente materialista, que acreditava que todos os problemas humanos poderiam ser resolvidos com o dado de uma quantidade ilimitada de bens materiais" (POLANYI, 2000, p. 58); afirmação que não contradiz em nada à realidade empírica à qual estamos tendo acesso, como evidenciam as constantes estimativas futuras feitas pelo agronegócio. Estas, ao darem como certo o aumento da produção a curto e longo prazo, não somente não dão importância nenhuma aos demais fatores ambientais, sociais e políticos com os quais se poderia estar interferindo, como transmite a ideia da existência de uma quantidade ilimitada de bens num planeta de recursos limitados.

Por sua parte, essa lógica economicista se insere, para poder justificar-se, dentro de um discurso mais amplo que poderia ser entendido como desenvolvimentista. A título de exemplo, podemos tomar as palavras proferidas pelo então ministro da Integração Nacional Helder Barbalho (hoje em dia governador do Estado do Pará) quem, coincidentemente ou não, foi também ministro chefe da Secretaria Nacional de Portos entre os anos de 2015 e 2016. Barbalho sobre o Arco Norte disse o seguinte:

Precisamos mostrar que o Arco Norte é a garantia para o Brasil ser mais competitivo no mercado internacional. Só assim os Estados que estão acima do Centro-Oeste terão condições necessárias de competir. (...) O mercado internacional precisa sentir segurança para aplicar seu capital e executar o que planeja. Além disso, o Brasil precisa dialogar e entender que sua regulação não pode ser excessiva. É necessário um ambiente mais desburocratizado em nosso país para incentivar o desenvolvimento. Precisamos consolidar novos empreendimentos porque isso significa geração de emprego e renda. (Ex-ministro Helder Barbalho - grifos meus) ${ }^{6}$.

\footnotetext{
5 Arco Norte: Um desafio logístico. Centro de Estudos e Debates Estratégicos, Consultoria Legislativa. Brasília: Edição Câmera, 2016.

6 Arco Norte é garantia para competitividade do País, afirma ministro. Disponível em: <http://www.brasil.gov.br/noticias/infraestrutura/2016/12/arco-norte-e-garantia-para-competitividade-do-pais-afirma-ministro>. 23/12/2016. Acessado em: 20/12/2018.
} 
Na fala, fica claro que o Arco Norte seria necessário tanto para o "desenvolvimento" da região como para o “desenvolvimento" do país. Porém, o que não chega a ficar completamente claro é o significado real dessa palavra tão utilizada e naturalizada nos dias de hoje. Sobre o assunto, Gustavo Esteva (2000) realizou um trabalho bastante minucioso ao rastrear as origens da palavra "desenvolvimento", remetendo-se para isso até meados do século XVIII, aos seus primeiros usos dentro da biologia. Nesta área de conhecimento, num primeiro momento, entendeu-se "desenvolvimento" como o processo normal pelo qual os organismos atingiam o seu potencial genético. Num momento posterior, o termo passou a ser entendido como a transformação destes organismos sempre para uma forma mais perfeita, dando-lhe a aquela palavra um sentido similar ao de "evolução". Além disso, Esteva comenta também como os usos do "desenvolvimento" extrapolaram o campo biológico para se inserirem dentro da esfera do social, ao ser utilizado tanto por naturalistas como por historiadores e filósofos.

Mesmo com uma carga forte de ambiguidade, mantida até hoje, a ideia de mudança favorável manteve-se vigente, sempre com relação a um único modelo ou lei geral e unidirecional, numa argumentação similar à trazida pelo evolucionismo cultural nos primórdios da antropologia. Mas se por um lado as teorias evolucionistas parecem ter sido ultrapassadas nas ciências sociais, o mesmo não aconteceu fora da acadêmia, onde "o modelo de produção industrial, que era nada mais do que uma entre as muitas formas de vida social, tornou-se por definição o estágio final de um caminho unilinear para a evolução social" (ESTEVA, 2000, p. 63).

Com base nessas breves considerações podemos voltar a analisar sob um outro olhar as palavras do ex-ministro da Integração Nacional aqui citadas, principalmente quando este faz referência ao "desenvolvimento" como finalidade máxima para a qual deveriam orientar-se todas as demais ações. Estas poderiam consistir, como no exemplo trazido, na flexibilização ou desburocratização das leis para poder incentivar os investimentos do capital internacional, o qual poderá contribuir à construção de novos empreendimentos como os já planejados dentro do Arco Norte. E é nesse sentido que se pode passar a enquadrar a PL $\mathbf{n}^{\mathbf{0}} \mathbf{3 . 7 2 9 / 2 0 0 4}$ citada na introdução do artigo, a qual precisamente procura flexibilizar o licenciamento ambiental para incentivar a construção de empreendimentos industriais sem o entrave da "burocracia" que "limita e afasta" a inversão econômica.

\section{PORTOS EM SANTARÉM}

Considerando a consolidação do Arco Norte como nova rota de exportação do agronegócio, entendemos a importância atribuída ao município de Santarém como lugar estratégico para a construção de portos que possam favorecer ao incremento da atividade exportadora. É verdade que outros municípios do Oeste do Estado do Pará já vêm sofrendo mudanças a causa da construção de complexos portuários, dentre os quais o caso mais representativo é o distrito de Miritituba, no município de Itaituba, que desde 2014 tem se convertido em um ponto importante na nova rota do escoamento de grãos e cereais ${ }^{7}$

Porém, mesmo com a existência de vários portos já instalados em Miritituba, a localização do município de Santarém continua gerando interesse no setor empresarial como possível cenário para a instalação de complexos portuários. Isto principalmente devido à profundidade que o canal de acesso ao rio Tapajós atinge perto deste município, podendo-se receber ali a entrada de navios tipo Panamax ${ }^{8}$, os quais possibilitariam o comércio marítimo intercontinental de grandes quantidades

7 Desde Sorriso, município produtor de soja localizado ao Norte de Mato Grosso, para escoar a produção pelo Porto de Santos era preciso que os caminhões percorressem uma distância de $2200 \mathrm{~km}$. Agora, pelo Arco Norte, estes caminhões têm que percorrer somente $1100 \mathrm{~km}$ até os portos de Miritituba, a metade da distância antes percorrida, o que se traduz numa grande redução dos preços dos fretes.

Panamax é um termo que faz referência aos navios que, devido às suas dimensões, alcançaram o tamanho limite (comprimento de 305 m,

PÉREZ, Diego. O componente étnico no licenciamento ambiental de grandes projetos de desenvolvimento... In: Cadernos do Lepaarq, v. XVI, 
de soja e milho. Precisamente este tipo de exportação de grande escala não é possível de se realizar em Miritituba, onde a pequena profundidade do rio faz com que os navios de maior porte não possam ingressar. Por esse motivo o escoamento da soja é ali realizado por meio de barcaças que ${ }^{9}$, seguindo seu percurso pela hidrovia Teles Pires-Tapajós, em algum momento terão que escoar novamente a produção transportada para navios maiores.

Cabe assinalar também que no município de Santarém atualmente existem dois grandes portos dedicados, um deles parcialmente e o outro por completo, ao escoamento de grãos e cereais. O primeiro destes portos é o Porto da Companhia Docas do Pará (CDP), e o segundo é o conhecido como o "Porto da CARGILL", construído pela empresa multinacional de mesmo nome. As construções destes portos foram concluídas, respetivamente, nos anos de 1974 e 2000, sendo um prelúdio do que décadas depois viria a ser formalmente proposto como um projeto desenvolvimentista maior pensado para toda a região.

Por sua parte, já no ano de 2014, com a nova regulamentação da lei de portos em vigor, pelo menos três empresas se mostraram realmente interessadas em construir Terminais Portuários de Uso Privado (TUP) no município de Santarém com a finalidade de exportar grãos por meio da nova rota traçada pelo projeto do Arco Norte. A EMBRAPS foi a empresa que mais avançou com os processos de licenciamento ambiental ${ }^{10}$, estando muito perto de obter a Licença Prévia (LP) em fevereiro de 2016. Por isso, foi também a única das empresas que teve que tornar público as caraterísticas do porto que pretendia construir.

\section{O PORTO DA EMBRAPS}

O Porto da EMBRAPS, tecnicamente chamado de Terminal de Exportação de Granel Solido da EMBRAPS, ficou popularmente conhecido como o Porto de Maicá devido à localização planejada para sua construção, a chamada "boca" do Lago de Maicá, localizada na margem direita do rio Amazonas. Alguns representantes da empresa tentaram esclarecer, mediante entrevistas oferecidas a meios de comunicação, que o Porto não seria implantado no Lago de Maicá e sim num terreno próprio de $502.788 \mathrm{~m}^{2}$ (com $279.340 \mathrm{~m}^{2}$ de área a ser construída), localizado no bairro denominado Área Verde. É certo que algumas das instalações do projeto portuário seriam construídas numa área que corresponde a esse bairro, mas é justamente ali onde se encontra também uma das principais “bocas” ou vias de acesso ao lago de Maicá.

Como consta na própria cartilha física que a empresa distribuiu, e levando em conta a contextualização feita até agora, a EMBRAPS reconhece que o projeto de construção do Porto foi elaborado com a finalidade de otimizar os processos de transporte, armazenagem e exportação de graneis sólidos. Dessa maneira, a empresa pretendia-se posicionar como alternativa para o escoamento da produção de grãos do Centro-Sul do país, trazendo com isso, como consta textualmente na cartilha, "geração de emprego, renda e desenvolvimento para nossa região, e consequentemente contribuindo para o crescimento de todos" ${ }^{11}$. Foi interessante observar a argumentação da cartilha porque ela sintetizou o funcionamento dos discursos utilizados como justificativas para a instalação de grandes projetos de infraestrutura, os quais, além dos argumentos económicos, assinalam também as contribuições que os projetos gerariam em favor do "desenvolvimento de todos" (BRONZ, 2016; RIBEIRO, 2015).

\footnotetext{
"boca" de 33,5m e calado de 26 m) para passar nas eclusas do Canal do Panamá até 2016, quando o canal foi ampliado.

9 Embarcação de fundo chato, reforçada, usada para transportar grandes quantidades de cargas.

10 A EMBRAPS é uma empresa fundada no município de Santarém no ano de 2012, cujo responsável e representante legal é o economista Pedro Riva, natural de Rio Grande do Sul e proprietário rural de Mato Grosso.

11 Cartilha de apresentação do projeto da EMBRAPS recebida pessoalmente no local da empresa, na Av. Mendonça Furtado, 1680 A- Sta. Clara, Santarém/PA.
}

PÉREZ, Diego. O componente étnico no licenciamento ambiental de grandes projetos de desenvolvimento... In: Cadernos do Lepaarq, v. XVI, 
Por sua parte, o terminal portuário da EMBRAPS estava projetado para ser composto por 3 estruturas, sendo estas o terminal aquaviário, o terminal graneleiro e finalmente o pátio regulador de carretas. Além disso, os dados fornecidos pelo RIMA nos informam que a construção do porto estava planejada para ser realizada mediante duas fases; a primeira fase iria durar em média 24 meses a partir de obtida a licença de instalação (LI), ao termino da qual, e uma vez obtida a licença de operação (LO), se começaria com a movimentação de grãos. Se estimava movimentar no primeiro ano de funcionamento uma quantidade de 4,8 milhões de toneladas de graneis sólidos, isto devido a que nessa primeira fase iriam a se construir no terminal somente 2 armazéns graneleiros dos 4 projetados.

Precisamente a segunda fase de construção, que previa uma duração máxima de 18 meses, pretendia concluir, além de outras obras de ampliação dentro do terminal, a construção dos outros 2 armazéns. Os 4 armazéns funcionando em conjunto pretendiam movimentar até 7,92 milhões de toneladas de graneis sólidos por ano.

\section{LICENCIAMENTO AMBIENTAL DA EMBRAPS}

No Brasil o licenciamento ambiental vigente está previsto no artigo 10 da lei no 6.938, de 31 de agosto de 1981, na resolução do Conselho Nacional do Meio Ambiente (CONAMA) n ${ }^{\circ}$, de 23 de janeiro de 1986, no inciso 4 do artigo ${ }^{\circ}$ 225 da constituição de 5 de outubro de 1988, no artigo 17 do Decreto n $^{\circ}$ 99.274, de 06 de junho de 1990, e na resolução do CONAMA nº 237, de 19 de dezembro de 1997.Por sua parte, a resolução do CONAMA $n^{\circ} 1$, por meio do seu artigo $n^{\circ} 2$, institui a obrigatoriedade do Estudo de Impacto Ambiental, sendo estes o Estudo de Impacto ambiental e o seu Relatório de Impacto ambiental correspondente (EIA/RIMA). Este último deveria ser um relatório conclusivo, em certa forma encarregado de "traduzir" e sintetizar os termos técnicos e demais informações levantadas no EIA.

A EMBRAPS, com a intenção de dar início ao processo de licenciamento ambiental que pudesse viabilizar a construção do chamado Porto de Maicá, procurou o órgão ambiental competente ${ }^{12}$. Por sua parte, para a elaboração do EIA/RIMA, o artigo $n^{\circ} 7$ da resolução CONAMA n 1 estipula que este deverá ser realizado por uma equipe multidisciplinar habilitada; a mesma que será a responsável dos resultados técnicos apresentados, não podendo depender direta ou indiretamente do proponente do projeto. Foi assim que a empresa passou a contratar os serviços da Fundação de Amparo e Desenvolvimento da Pesquisa (FADESP), instituição de direito privado de apoio à pesquisa cientifica, a qual seria a encarregada de realizar o EIA/ RIMA do projeto portuário ${ }^{13}$.

O processo de licenciamento ambiental iniciado pela EMBRAPS, em seu conjunto, apresentou uma série de irregularidades que foram por mim observadas em outro momento (PÉREZ, 2017) ${ }^{14}$. As mesmas fizeram com que o

12 No Estado de Pará o licenciamento ambiental pode ser conduzido por meio da Secretaria Municipal de Meio Ambiente-SEMMA/PA, órgão de competência municipal; por meio da Secretaria de Estado de Meio Ambiente e Sustentabilidade- SEMAS/PA, órgão de competência estadual; ou, por último, por meio do IBAMA, órgão de competência federal. A EMPRAPS deu entrada ao processo de licenciamento junto com a SEMAS/ PA, o que foi questionado posto que, ao estar projetada a construção do Porto na margem direita do Rio Amazonas, dito empreendimento passaria a afetar diretamente a um rio federal situado entre os limites ecológicos da Floresta Amazônica, abarcando mais de dois estados. Por isso, a competência do órgão licenciador deveria ser federal e não estadual, como terminou sendo.

13 "A Fundação de Amparo e Desenvolvimento da Pesquisa- FADESP é uma instituição de direito privado, sem fins lucrativos, que tem como objetivo apoiar o desenvolvimento científico, social e tecnológico da Amazônia. Atua como gerenciadora de recursos nas mais variadas áreas do conhecimento. Criada em 1977 para dar suporte às atividades da UFPA, é, hoje, é um dos grandes agentes estratégicos da região Norte". <http://www. portalfadesp.org.br/pagina.asp?id_pagina=214>. Acessado em:02/01/19.

14 Para mais informação sobre as irregularidades presentes no processo de licenciamento ambiental da EMPRAPS consultar PÉREZ, Diego. As comunidades quilombolas de Santarém/PA e o Porto de Maicá: os efeitos sociais de um empreendimento anunciado. Trabalho de Conclusão de Curso. Antropologia/ICHF, UFF, Niterói, dezembro de 2017, p.59-82. 
licenciamento ambiental fosse alvo de vários processos judiciais, dois dos quais terminaram por suspender o mesmo, se encontrando o projeto de construção do Porto de Maicá suspendido até agora ${ }^{15}$.

\section{A INVISIBILIZAÇÃO DAS COMUNIDADES QUILOMBOLAS DE SANTARÉM NO EIA/RIMA}

Considerando o "diagnóstico socioeconômico" apresentado no EIA/RIMA vale a pena discutir a forma em que se fez referência às comunidades quilombolas da região. De fato, o referido estudo passou a defender uma tese na qual se afirmava que a construção do Porto da EMBRAPS “não apresentaria elementos que possam causar danos socioambientais diretos nestas comunidades (quilombolas)" (RIMA, 2015, p. 41). Mas, a principal irregularidade naqueles estudos foi a invisibilização à qual foram sujeitas as comunidades quilombolas, como consta na fala de Dileudo, presidente da FOQS: "Nós não existimos, não existe comunidade aqui, não existe nada" (Entrevista realizada a Dileudo, 14 de fevereiro do 2017).

Aquele tipo de apagamento das comunidades quilombolas ao qual Dileudo se referiu, me fez pensar em três tipos diferentes de invisibilização postos em prática pela FADESP na realização do EIA/RIMA. Seguindo o raciocínio aqui proposto, para um primeiro grupo de oito das doze comunidades quilombolas agrupadas na FOQS, o processo de invisibilização teria sido total, ao ponto de nem sequer terem chegado a ser mencionadas nos estudos. Seis daquelas oito comunidades apagadas de maneira total contavam inclusive com a Certidão de Autoreconhecimento emitida pela Fundação Cultural Palmares (FCP) e com seus respectivos Relatórios Técnicos de Identificação e Delimitação (RTID) concluídos.

Num segundo grupo estão reunidas às quatro comunidades quilombolas da FOQS restantes, as quais, por se encontrarem a uma distância muito próxima do lugar onde se pretende instalar o Porto, não puderam ser invisibilizadas totalmente pela FADESP, chegando a ser mencionadas, mesmo que em alguns casos muito brevemente, dentro do EIA/RIMA. São elas a comunidade quilombola de Bom Jardim, localizada a 10,4 Km da Área Diretamente Afetada (ADA) do projeto, na região de Maicá, no planalto santareno; a comunidade quilombola de Saracura, localizada a 7,5Km da ADA do projeto, na margem esquerda do Rio Amazonas, na região de Tapará; a comunidade quilombola de Arapemã, localizada numa ilha na margem esquerda do Rio Amazonas, na região de Uricurituba, a uns escassos $4 \mathrm{~km}$ de onde tinha sido projetado o Terminal Portuário; e a comunidade quilombola de Pérola de Maicá, cuja organização é a Associação de Moradores Remanescentes do Quilombo de Arapemã Residentes em Maicá (AMRQARM), a qual se encontra num bairro localizado exatamente ao lado do bairro onde se planejava instalar o empreendimento.

A meu ver, as três primeiras comunidades quilombolas deste segundo grupo teriam sido vítimas de um outro tipo de invisibilização, não total mas parcial. Isto porque, mesmo tendo sido mencionadas no EIA/RIMA, a saída que os técnicos da FADESP encontraram foi a de afirmar que o empreendimento não provocaria impactos socioambientais diretos sobre ditas comunidade.

\footnotetext{
15 A justiça determinou pela suspensão do licenciamento ambiental da EMBRAPS graças a uma Ação Civil Pública com pedido de liminar apresentada em conjunto pelo MPF/PA e o MPE/PA no dia 15 de fevereiro de 2016. O pedido de liminar foi outorgado no dia 12 de abril de 2016 pelo juiz da $2^{\text {a }}$ Vara da Subseção Judiciaria de Santarém/PA, e a decisão foi posteriormente ratificada em Brasília, no dia 24 de maio de 2016 , pelo Tribunal Federal Regional da Primeira Região. Assim, o licenciamento ambiental da EMPRAPS, e, por conseguinte, o projeto de construção do Porto de Maicá, se encontram suspensos até que os responsáveis possam comprovar a realização da consulta prévia, livre e informada das comunidades quilombolas e demais populações tradicionais, assim como o prevê a Convenção no 169 da Organização Internacional do Trabalho (OIT), da qual Brasil é signatário desde o 2002.
} 


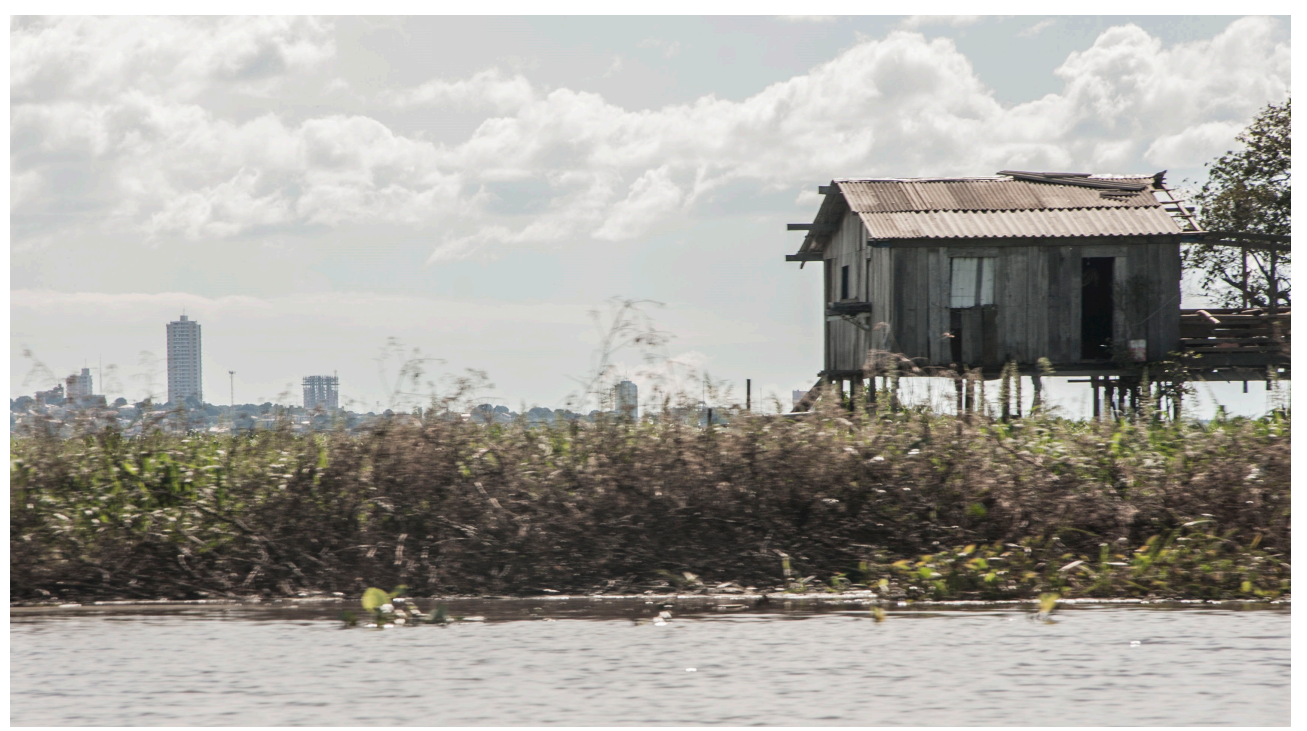

Figura 1: Vista do centro de Santarém desde a comunidade quilombola de Arapemã (observe-se alguns prédios no fundo), as quais estão separadas por uma distância de aproximadamente $6 \mathrm{~km}$. A distância entre a boca do lago de Maicá, onde se pretendia construir o Porto, e a comunidade de Arapemã é ainda mais curta, de aproximadamente 4km. Fonte: Acervo pessoal.

Por sua parte, a comunidade quilombola de Pérola de Maicá teria sofrido um terceiro tipo de invisibilização, neste caso não total nem parcial, mas sim forçada. Dita comunidade se encontra localizada na periferia da área urbana da cidade de Santarém, dentro bairro também chamado de Pérola de Maicá. Este, que apresenta caraterísticas próprias de uma área rural, faz fronteira com o bairro de Área Verde, onde se planejava instalar o Porto da EMBRAPS. Ambos bairros compartilham a rua Niterói (que finaliza no Lago de Maicá) como um dos seus limites, mas a comunidade quilombola de Pérola de Maicá foi catalogada no EIA/RIMA como fora da ADA pelo empreendimento.

Ao se contar com a presença de uma comunidade quilombola localizada tão próxima de onde se planejava instalar o Terminal Portuário, a solução que os técnicos da FADESP encontraram para poder facilitar a viabilidade do projeto em questão foi a de negar o componente étnico da mesma. Esta ação foi realizada sem dar importância à certidão de Autoreconhecimento que a FCP emitiu no ano de 2007. Cabe assinalar também que a comunidade quilombola de Pérola de Maicá já deu início ao processo de titulação do território quilombola junto ao INCRA, contando, inclusive, com boa parte do RTID já concluído.

Sem levar em conta a autoidentificação como critério fundamental para a definição de grupo, que se sustenta num arcabouço jurídico internacional mediante a Convenção n ${ }^{\circ} 169$ da OIT, o EIA deu a entender que a comunidade em questão, pelo fato de se encontrar numa área de periferia urbana, teria deixado de ser quilombola, como consta no próprio documento:

\footnotetext{
Ao abandonarem a ilha eles (os moradores agrupados na AMRQARM) deixaram o território quilombola para trás e passaram a viver de acordo com as regras sociais e políticas do município. Mesmo se auto afirmando quilombolas, tendo formado uma associação, eles não atendem aos requisitos legais estabelecidos no artigo $\mathrm{n}^{\circ}$ 3 do Decreto $n^{\circ} 6.040$, de fevereiro de 2017 (...). Diante do que diz a lei, a Fundação Cultural Palmares ao certificar o grupo de ex-moradores da ilha de Arapemã, residentes no bairro Pérola de Maicá, desde 1980, área urbana da cidade de Santarém, como "comunidade remanescente de quilombo", ela reconhece a identidade autoafirmativa do grupo, mas não é legalmente possível designar a área ocupada por eles no bairro de Pérola de Maicá como sendo território quilombola, pois os mesmos não possuem formas próprias de organização social, não ocupam e não usam aquele território e os recursos naturais como condição para a sua reprodução cultural, social, religiosa, ancestral e econômica, e nem utilizam conhecimentos, inovações e práticas gerados e transmitidos pela tradição da cultura negra, e vivem igualmente sob as mesmas determinações sociais, econômicas, culturais, políticas e religiosas que os outros munícipes moradores do bairro Pérola de Maicá. (EIA, 2016:586 - grifos meus).
} 


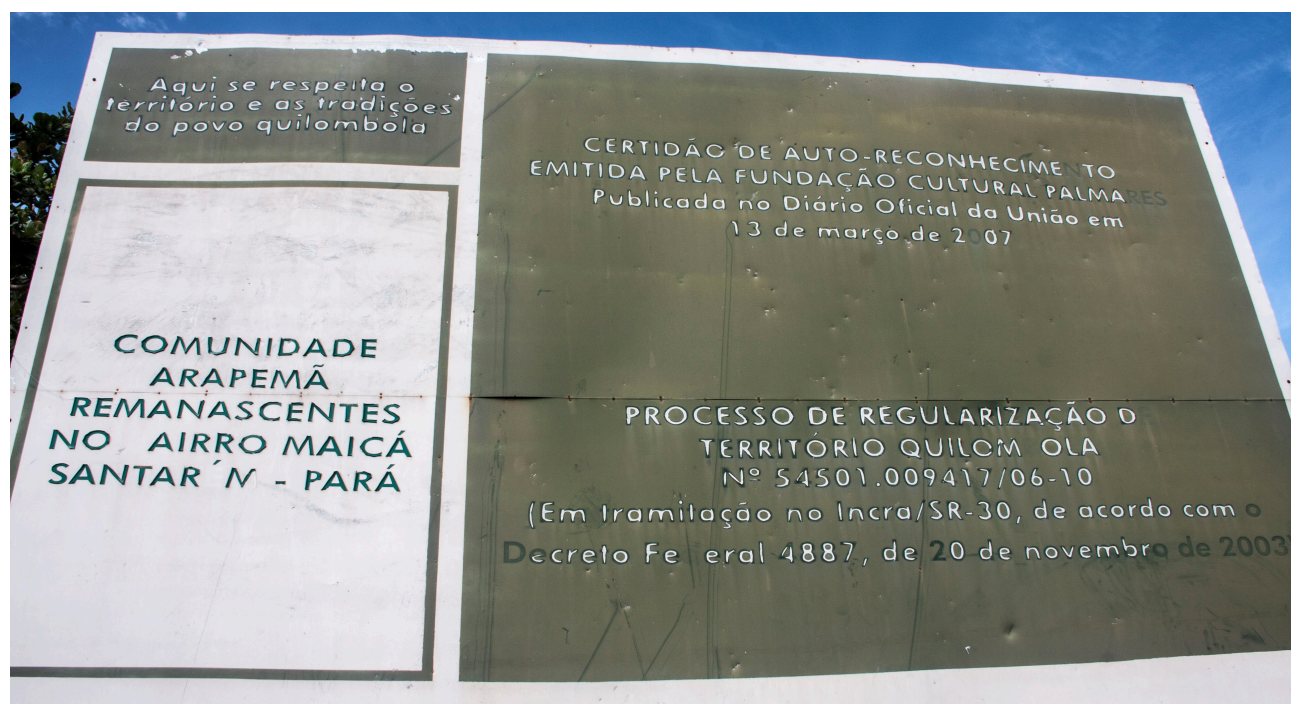

Figura 2: Placa que faz referência à obtenção da Certidão de Autoreconhecimento obtida pela AMRQARM, no dia 01 de março de 2007, publicado no Diário Oficial da União em 13 de março de 2007. A placa se encontra colocada do lado de fora da sede da associação quilombola, no bairro Pérola de Maicá. Pode-se ler que o processo de regularização do Território Quilombola já se encontra em tramitação no INCRA/SR-30, com o n ${ }^{\circ}$ 54501.009417/06-10, de acordo com o Decreto Federal 4887, de 20 de novembro de 2003. Por último, lê-se também, “Aqui se respeita o Território e as tradições do povo quilombola". Fonte: Acervo pessoal.

O trecho extraído do EIA apresenta alguns dos argumentos utilizados pelos realizadores do EIA/RIMA para não reconhecer como território quilombola a área ocupada pela comunidade quilombola de Pérola de Maicá. Um desses argumentos fez referência ao deslocamento realizado por grande parte das pessoas que hoje em dia são moradores do bairro de Pérola de Maicá e da comunidade quilombola ali localizada. Efetivamente, no passado muitos deles se viram obrigados a sair da ilha de Arapemã, o lugar onde tinham as suas residências. Este fato histórico nunca foi negado pelos membros da comunidade quilombola de Pérola de Maicá, os quais inclusive passaram a incluir uma referência direta a dito acontecimento no próprio nome da nova associação que fundaram e na qual passaram a ser organizar, a Associação de Moradores Remanescentes do Quilombo de Arapemã Residentes em Maicá-AMRQARM.

Sabe-se que essa mudança para fora da ilha de Arapemã se deu no final dos anos 1980, e se deveu em grande parte ao fenômeno das chamadas "terras caídas"16 , que foi muito intenso durante aqueles anos. Esta caída literal de grandes porções de terra obrigou a vários dos moradores de Arapemã a se deslocarem pela perda das suas casas, o que sempre formou parte da própria dinâmica da organização local das comunidades de toda a região de várzea. A novidade nesse caso em particular foi que a comunidade de Arapemã não contava com lugares disponíveis para realocar a grande quantidade de famílias que tinham perdido as suas casas devido ao aumento demográfico que a comunidade tinha registrado nas últimas décadas. Foi por isso que muitas famílias passaram a ocupar alguns lotes de terra disponíveis na periferia de Santarém, os quais foram cedidos pelo prefeito da época.

16 As chamadas "terras caídas" e "terras crescidas" são fenômenos naturais que se encontram em estreita relação com as estações climáticas conhecidas como o "verão" e o "inverno" amazônico. É no período do "verão", quando o nível das aguas começa a descer, que as margens dos rios começam a ficar expostas a uma velocidade muito rápida, ficando assim cada vez mais pronunciadas as distancias que passam a separar a terra firme do nível do rio. Estas distâncias, que pode variar de 1 a 2 metros de altura, fazem com que as bases expostas das margens dos rios fiquem cada vez mais instáveis por causa da correnteza. Pouco a pouco a terra vai cedendo até que grandes pedaços de terra se desmoronam por completo, terminando depositados tanto no fundo como em margens opostas do rio, fazendo assim "cair" e "surgir" grandes pedaços de terra. 
O deslocamento não teria porque ser um impedimento, como sutilmente se tenta colocar no EIA, para que o grupo instalado no bairro de Pérola de Maicá possa passar a orientar as suas ações coletivas à reafirmação da sua identidade étnica de comunidade quilombola frente ao Estado. De outra forma, estar-se-ia argumentando em favor de uma noção de identidade limitada exclusivamente pelas fronteiras territoriais do grupo, deixando-se de lado às noções orientadas por um entendimento no qual a identidade étnica é reafirmada socialmente, e construída em base na crença presumida de uma origem em comum e na orientação das ações coletivas (WEBER, 2000, p. 270). No caso específico da comunidade quilombola de Pérola de Maicá, a presunção da origem comum evidentemente não se limitaria a seu passado recente ligado à comunidade quilombola de Arapemã. Através deste se remontaria a um passado muito mais distante, afirmando-se assim a existência de vínculos entre eles e os escravos que tempos atrás habitaram essa mesma região do Baixo Amazonas. Isto sem deixar de levar em conta que o passado ao qual se referem os membros desses grupos "não é o da ciência histórica, mas aquele em que se representa a memória coletiva" (POUTIGNAT\&STREIFF-FENART,1998 apud O’DWYER, 2002, p. 17).

Por sua vez, a referida citação do EIA também diz respeito à "perda da tradição da cultura negra” que a comunidade quilombola de Pérola de Maicá teria sofrido, reforçando-se assim, por colocá-lo de alguma maneira, a sua "não autenticidade étnica". Frente a esse argumento seria importante relembrar aqui a diferença existente entre a cultura como marcador de grupo e a cultura como limite do grupo (Eidheim,1969; Eriksen, 1991). Precisamente a maioria dos problemas se iniciam quando se confundem ambos termos e se passa a identificar os grupos étnicos como portadores de uma determinada cultura específica, sendo a etnicidade e a cultura duas noções distintas pensadas erroneamente de forma conjunta nesse contexto. A cultura pode ser entendida como aquilo que o ser humano utiliza para interpretar e agir no mundo, não sendo intocável ou invariável porque se encontra em fluxo, numa variação continua que se enriquece constantemente com a interação social. Alguns autores têm definido à cultura como algo que "se herda, usa, transforma, adiciona e transmite" (FIRTH apud HANNERZ, 1997, p. 12), e é ali onde radica sua variabilidade e autenticidade. Precisamente Edward Sapir entendia à cultura como autentica quando não era uma mera herança do passado passivamente aceita, precisando da participação criadora dos membros da comunidade (SAPIR, 1971, p. 299).

Sobre o debate da etnicidade, alguns dos clássicos desdobramentos teóricos de Barth, especialmente aqueles que incluem as suas reflexões sobre os grupos étnicos (2000; 2005), nos ajudaram a desconstruir os argumentos de "invisibilidade" encontrados no EIA/RIMA. Assim, para o autor, a prevalência dos grupos étnicos no tempo não é dada pela manutenção dos seus traços culturais, mas sim pela criação de fronteiras criadas e mantidas pelo próprio grupo, as quais perduram mesmo com a mudança de caraterísticas culturais (BARTH, 2000). É importante esclarecer que a existência desses limites não impede a transposição das fronteiras sociais (que podem ter contrapartida territorial), podendo inclusive chegar a ser alterada a própria forma de organização do grupo. Por essas razões, a necessidade de tornar como foco central das investigações as fronteiras étnicas que definem o grupo e não o conteúdo cultural por elas delimitado (BARTH, 2000, p. 32), procurando conhecer os limites entre aqueles situados "dentro" e "fora" das mesmas, sendo esse o processo mediante ao qual os integrantes criam seus próprios critérios de pertencimento definidos pelo antropólogo norueguês como sinais diacríticos. 


\section{CONSIDERAÇÕES FINAIS}

São estes tempos difíceis para todos, em especial para os povos tradicionais, os quais já vinham tendo ameaçadas, mesmo durante os governos de caráter mais progressistas, as suas condições de existência. Como apontou Maybury-Lewis:

Não importa que as populações indígenas (ou tradicionais) sejam grandes ou pequenas, que sejam ubíquas ou distantes, que vivam em países dominados por regimes de direita ou esquerda, pois são exortadas ou forçadas a abandonar suas culturas em nome do desenvolvimento nacional. (MAYBURY-LEWIS,1983, p. 110)

Foi precisamente em prol da natureza desenvolvimentista do projeto de construção do Porto de Maicá que, a EMBRAPS, num claro ato de rejeição às condições contrastivas de existência daqueles povos, configurou mais um caso de racismo institucional, ao entender "o sofrimento que por acaso possa ser infligido a tais povos e populações seria, em parte, justificável” (O’DWYER, 2013, p. 128).

Na sexta-feira 14 de dezembro de 2018, no encerramento das atividades legislativas anuais, os vereadores do município de Santarém/PA incluíram uma emenda à minuta do Plano Diretor do Município (2019-2021), a qual pode permitir a implantação de terminais portuários no Lago do Maicá, hoje em dia configurado como área de preservação ambiental ${ }^{17}$. Representantes das comunidades quilombolas, indígenas e ribeirinhas da região, que em muitos casos dependem diretamente do uso do Lago de Maicá, mais uma vez foram invisibilizadas, não sendo convocados a dita reunião.

Passaram-se trinta anos desde a aprovação do artigo no 68 dos Atos das Disposições Constitucionais Transitórias (ADCT), e entendemos não ser possível continuarmos mantendo uma ideia desfasada e cristalizada do termo quilombo, mais orientado ao passado do que ao presente. Como Alfredo Wagner (2002) apontou, é momento de passar a pensar não tanto em termos do que o quilombo foi, e sim no que o quilombo é hoje em dia. Passar a pensar como se deram os processos no quais se formaram ditas identidades, que abriram a possibilidade desses grupos alcançarem novas potencialidades para encaminhar e constituir o curso das suas próprias vidas. Nesse sentido, situações concretas, como a assinalada recentemente, tem demostrado que, mesmo com as limitações que possam existir, a ciência antropológica pode ser de fato utilizada como um "instrumento de reconhecimento público de direitos constitucionais” (O’DWYER, 2002, p. 21).

17 Na contramão de decisão popular, vereadores de Santarém aprovam inclusão de Lago do Maicá como área portuária. Disponível em:<https://racismoambiental.net.br/2018/12/17/na-contramao-de-decisao-popular-vereadores-de-santarem-aprovam-inclusao-de-lago-do-maica-como-area-portuaria/>. 17/12/2018. Acessado em: 07/01/2019. 


\section{REFERENCIAS BIBLIOGRÁFICAS}

ALMEIDA, Alfredo Wagner B. Os Quilombos e as novas etnias. In: O'DWYER, Eliane C. Quilombos: identidade étnica e territorialidade. Rio de Janeiro: FGV, 2002. p.43-82.

BARTH, Fredrik. Os grupos étnicos e suas fronteiras. In: .O guru, o iniciador e outras variações antropológicas. Tradução: John Cunha. Rio de Janeiro: Contra Capa Livraria, 2000. p.25-67. Etnicidade e o Conceito de Cultura. Antropolítica, Niteroi: [on-line], n.19, p.15-30. $2^{\circ}$ semestre, 2005.

BRASILEIRO, Sheila \& SAMPAIO, José Augusto. Sacutiaba e Riacho de Sacutiaba: uma comunidade negra rural no oeste baiano. In: O’DWYER, Eliane C. Quilombos: identidade étnica e territorialidade. Rio de Janeiro: FGV, 2002. p.83-108.

BRONZ, Deborah. Nos bastidores do licenciamento ambiental: uma etnografia das práticas empresariais em grandes empreendimentos. Rio de janeiro: Contra Capa, 2016.

EIDHEIM, Harald. When ethnic identity becomes a social stigma. In: BARTH, Fredrik. Ethnic groups and boundaries. Oslo: Norwegian Univ. Press., 1969. p. 39-57.

ERIKSEN, Thomas H. The cultural contexts of ethnic differences. Man, London: [on-line], n.26(2), p.127-144. mar, 1991.

ESTEVA, Gustavo. Desenvolvimento. In: SACHS, Wolfgang. Dicionário do Desenvolvimento. Tradução: Vera Lúcia M. Joscelyne, Susana de Gyalokay, Jaime A. Clasen. Petrópolis: Vozes, 2000. p.59-84.

HANNERZ, Ulf. Fluxos, fronteiras, híbridos: palavras-chave da antropologia transnacional. Mana: Estudos de Antropologia Social, Rio de Janeiro: [on-line], n.3, p.7-39. $1^{\circ}$ semestre, 1997.

MAYBURY-LEWIS, David. Vivendo Leviatã: Grupos Étnicos e o Estado. Anuário Antropológico, Brasília: [on-line], p.103118,1983

O’DWYER, Eliane C. Os Quilombos e as práticas profissionais dos antropólogos. In: Quilombos: identidade étnica e territorialidade. Rio de Janeiro: FGV, 2002. p.13-42.

Desenvolvimento e povos tradicionais. In: Dicionário temático desenvolvimento e questão social: 81 problemáticas contemporâneas. São Paulo: Anna Blume, 2013. p.123-129.

PÉREZ, Diego. As comunidades quilombolas de Santarém/PA e o Porto de Maicá: os efeitos sociais de um empreendimento anunciado. Trabalho de Conclusão de Curso. Antropologia/ICHF, UFF, Niterói, dezembro de 2017.

POLANYI, Karl. A grande transformação. As origens da nossa época. Tradução: Fanny Wrobel. Rio de janeiro: Editora Campus, 2000.

RIBEIRO, Gustavo Lins. Quanto maior melhor? Projetos de grande escala: Uma forma de produção vinculada à expansão de sistemas econômicos. In: OLIVEIRA FILHO, J.P.; COHN, C. (Orgs.). Belo Monte e a questão indígena. Brasília: ABA Publicações, 2015. p.50-69.

SALLES, Vicente. O negro no Pará sob o regime da escravidão. Coleção Amazônica. Serie José Veríssimo. Rio de Janeiro, Fundação Getúlio Vargas, Serv. De publicações [e] Univ. Federal do Pará, 1971.

SAPIR, Edward. Cultura autentica e espúria. Comunicação, linguagem, cultura, São Paulo: Escola de comunicações e artes, 1971. p.282-312.

WEBER, Max. Relações comunitárias étnicas. In: Economia e sociedade: Fundamentos da sociologia compreensiva. Volume 1. Tradução: Regis Barbosa e Karen Elsabe Barbosa. Brasília DF: Editora da UnB, 2000. p.267-277. 